\title{
Numerical Analysis of Thermal Flow Characteristics Inside Waste Combustion Chamber with Multiple Thermal Plasma Jets
}

\author{
Received 4 November, 2021; revised 25 November, 2021; accepted 29 November, 2021
}

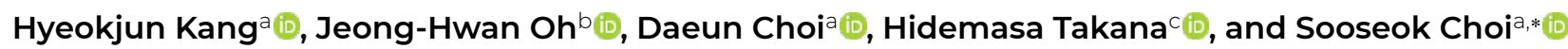 \\ a Department of Nuclear and Energy Engineering, Jeju National University, Jeju 63243, Republic of Korea \\ bElectric Energy Research Center, Jeju National University, Jeju 63243, Republic of Korea \\ cInstitute of Fluid Science, Tohoku University, Miyagi 980-8577, Japan
}

*Corresponding author E-mail: sooseok@jejunu.ac.kr

\begin{abstract}
Presently, the use of bituminous coals as a heating source in the cement industry has led to an increase in carbon dioxide emissions. In this study, the thermal flow characteristics inside a waste combustion chamber constituting multiple thermal plasma jets was numerically analyzed. The waste combustion process was applied as a heating source to produce the raw materials of cement. The design and operation of the waste combustion process were optimized through numerical analysis using the magnetohydrodynamics and computational fluid dynamics code. The thermal flow characteristics inside the waste combustion chamber were numerically analyzed in accordance with adjusting the chamber width, injection angle of the torch, and combustion air temperature. As a result, the temperature in the range of 1,600-2,200 K was widely distributed at the center of the chamber. The optimized conditions are as follows: $400 \mathrm{~mm}$ chamber width, $20^{\circ}$ injection angle, and 1,000 K combustion air temperature. The waste combustion chamber constituting multiple thermal plasma jets was constructed based on the numerical results. It was concluded that plasma jets generate a sufficient temperature to treat waste plastics.
\end{abstract}

Keywords: Multiple thermal plasma jets, Numerical analysis, Waste, Alternative fuel

\section{Introduction}

The domestic cement industry mainly consumes energy generated through the combustion of bituminous coal, which involves decarboxylation reactions and produces the raw materials of cement from clinker [1-3]. Currently, all of the bituminous coal used as a primary heating source in the cement industry is imported. A high consumption of bituminous coal thereby increases the running cost as well as carbon dioxide emissions, which particularly have a significant impact on the environment $[4,5]$.

Various energy-saving and pollution-reduction methods have been introduced, such as recycling waste plastics and other combustible wastes [6]. However, with the current technology, the use of waste fuels reduces the heating efficiency and negatively affects the cement production process because these fuels comprise plastics, tires, waste oil, and urban waste, whose incomplete combustion during the waste incineration treatment generates hazardous materials $[7,8]$.

The DC thermal plasma torch has the advantage of generating high temperatures in the range of $8,000-16,000 \mathrm{~K}$ at the torch exit and a plasma velocity of a few hundreds of meters per second [9]. This DC thermal plasma torch is used in various industries, such as waste treatment, spray coating, and nanomaterial synthesis $[10,11]$. Notably, in the semiconductor industry, the chemically reactive high temperature of the thermal plasma is appropriate to decompose fluorinated compounds with a high destruction and removal efficiency, thereby controlling the byproduct generation [12].

Therefore, it is necessary to develop a process technology to increase the energy efficiency and decrease the use of fossil fuels. This study is a numerical simulation for the multiple DC thermal torch system, which improves the treatment capacity of alternative waste fuels by using the magnetohydrodynamics (MHD) and computational fluid dynamics (CFD) code $[13,14]$. Through the analysis of the thermal flow characteristics, we optimized the design and operating conditions of the combustion system using alternative waste plastics.

\section{Simulation Method}

The high-temperature combustion system with multiple thermal plasma jets consists of combustion air and waste inlets, sixteen DC plasma torches, and a system outlet connected to the cement production process, as shown in Fig. 1. A total of 16 torches are injected into the space (eight torches on each side at $150 \mathrm{~mm}$ intervals) where the waste is burned on both sides. The detailed geometry is illustrated in Fig. 2. DC plasma torches with an individual power supply generate thermal plasma jets, while the waste is injected from the top of the reactor with combustion air.

The numerical simulation was conducted in two steps. First, the DC plasma torch characteristics were calculated by a self-developed MHD code, DCPTUN. The MHD code is based on several assumptions; optically thin, electrically neutral, turbulent, and under local thermodynamic equilibrium. This was considered for the coupled interaction among the arc current, self-induced magnetic field, and plasma flow inside the torch $[15,16]$. Then, the complex thermal flow inside the reactor was numerically analyzed by the commercial CFD code, ANSYS-FLUENT. The temperature and velocity profiles at the 


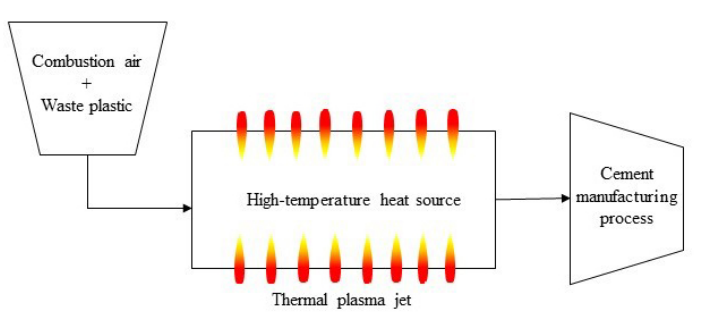

Figure 1. Schematic of the high-temperature combustion system with thermal plasma jets for the cement manufacturing process.

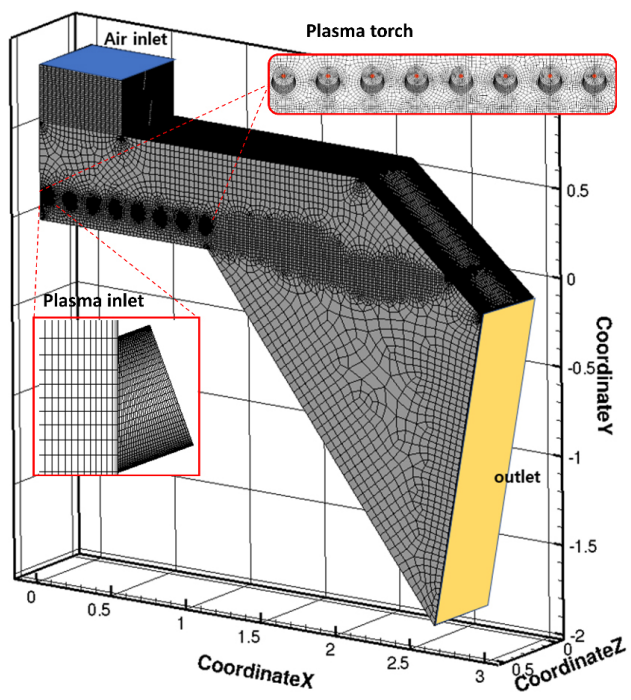

Figure 2. Schematic of the simulation domain and mesh grid.

DC torch exit calculated in the first step were combined to the FLUENT as the inlet boundary conditions and applied turbulent flow described by realizable k- $\varepsilon$ model, standard wall function [17-19]. In Fig. 2 , the 3 -D domain was formed with approximately $3,300,000$ nodes and 3,260,000 elements using the Design Modeler program in FLUENT. For the convergence of the calculation, nodes were densely configured for areas with high temperature and velocity gradients, such as thermal plasma injection holes.

The numerical conditions are summarized in Table I. Nitrogen was used as the discharge gas of the plasma at a flow rate of $110 \mathrm{~L} / \mathrm{min}$. We numerically analyzed the theraml flow inside the chamber by adjusting the air temperature, torch injection angle, and chamber width. The calculated arc voltage at a fixed current of $110 \mathrm{~A}$ was $216 \mathrm{~V}$. The characteristics of thermal flow inside the chamber were numerically analyzed by adjusting chamber width, injection angle of the torch, and the temperature of combustion air, as shown in Table I.

Table I. Numerical conditions for the waste combustion chamber with multiple DC plasma torches.

\begin{tabular}{c|c}
\hline \multicolumn{2}{c}{ Numerical conditions } \\
\hline Gas flow rate [L/min] & $\mathrm{N}_{2} 110$ \\
Chamber width [mm] & 400,500 \\
Torch injection angle $\left[^{\circ}\right]$ & 20,30 \\
Combustion air temperature $[\mathrm{K}]$ & 300,1000 \\
Current [A] & 110 \\
Calculated arc voltage [V] & 216 \\
\hline
\end{tabular}

(a)

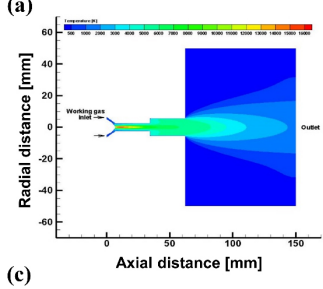

(c)

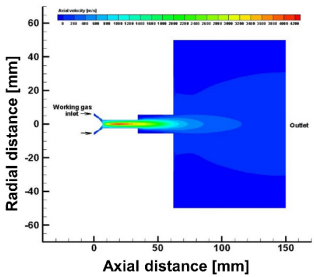

(b)

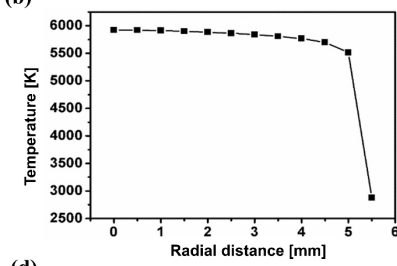

(d)

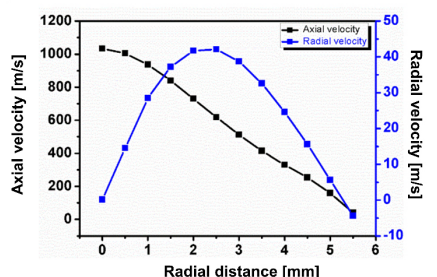

Figure 3. Numerical analysis results for the torch region: (a) temperature contour, (b) temperature profile at torch exit, (c) velocity contour, and (d) velocity profiles at torch exit.

\section{Results and discussion}

We performed the numerical simulation for the DC torch, which is used as a combustion heat source. The DC torch region was numerically analyzed for the 2-D mesh because of its axis-symmetric geometry. Figure 3 shows the thermal flow characteristics inside the DC torch region with the following operating conditions: $110 \mathrm{~L} / \mathrm{min}_{2}$ flow rate and $110 \mathrm{~A}$ current. The calculated arc voltage and input powers were $216 \mathrm{~V}$ and $24 \mathrm{~kW}$, respectively. As shown in Figs. 3(a) and 3 (b), a high temperature of $6,000 \mathrm{~K}$ was found at the center of the torch exit, along with an even temperature distribution of 3,000-5,000 K after the torch exit. The velocity contour and profiles inside the torch region are confirmed in Figs. 3(c) and 3(d). The axial velocity at the center of the torch exit was the highest $(1,000 \mathrm{~m} / \mathrm{s})$, whereas the radial velocity was the highest at a radial distance position of $2.5 \mathrm{~mm}$. These temperature and velocity profiles were used as the boundary conditions of the plasma inlet to simulate the chamber region.

Figure 4 shows the temperature contour and profiles at the center of the chamber in accordance with its width adjustment. In a chamber of $400 \mathrm{~mm}$ width, the maximum and minimum temperatures were approximately 1,300 and $800 \mathrm{~K}$, respectively, whereas for a $500 \mathrm{~mm}$ width, the maximum temperature was $900 \mathrm{~K}$. It was confirmed that an increase in the chamber width over $500 \mathrm{~mm}$ did not uniformly form a relatively high temperature over $800 \mathrm{~K}$ at its center. However, for a $400 \mathrm{~mm}$ width, a temperature of $800 \mathrm{~K}$ was widely distributed to the chamber exit. The plasma flame generated from both sides could be merged at the center of the chamber designed with a width under 400 $\mathrm{mm}$.

In accordance with adjusting the injection angle of the plasma torch, the temperature distribution at the center of the chamber was numerically analyzed, as indicated in Fig. 5. The injection angle was $20^{\circ}$ and $30^{\circ}$ at fixed conditions of a $400 \mathrm{~mm}$ chamber width, and $300 \mathrm{~K} \mathrm{com}-$ bustion air temperature. It was identified that a relatively low temperature from $600-1,100 \mathrm{~K}$ was formed for a $30^{\circ}$ injection angle of the plasma torch, and the temperature variation was significant at the position of torch injection. Herein, the thermal efficiency was low compared with that at a $20^{\circ}$ injection angle. The increase in the injection angle causes a short plasma flame length that does not reach the center of the chamber. It was revealed that the injection angle of the plasma torch has to be constructed under $30^{\circ}$.

Figure 6 shows the simulation results according to the changing temperature of combustion air, and this simulation was performed at fixed conditions for a $400 \mathrm{~mm}$ chamber width and a $20^{\circ}$ injection angle. The increase in combustion air temperature causes the improvement in temperature at the center of the chamber. In the case of a 1,000 
(a) $\mathrm{T}(\mathrm{K})$
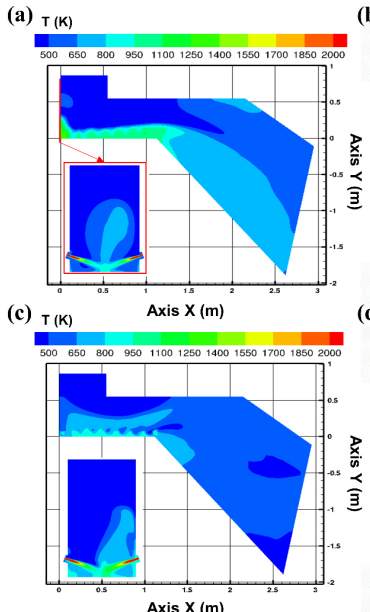

(d)
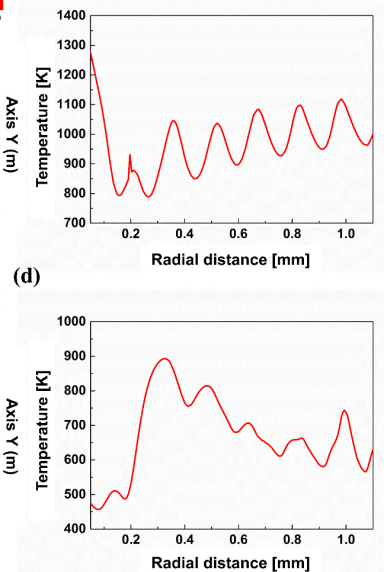

Figure 4. Numerical analysis results of the chamber region for the condition fixed at $20^{\circ}$ and $300 \mathrm{~K}:(\mathrm{a}, \mathrm{b})$ temperature contour and profile for a $400 \mathrm{~mm}$ width and (c, d) temperature contour and profile for a $500 \mathrm{~mm}$ width. (a) $T(K)$

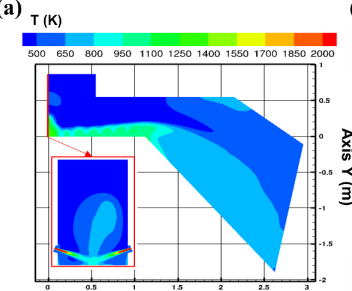

(c) $T(K)$

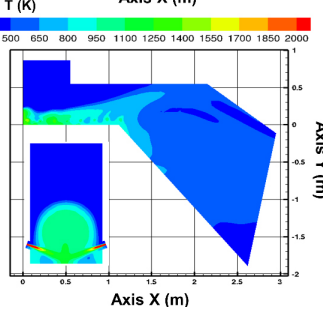

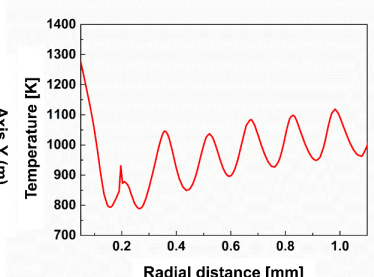

(d)

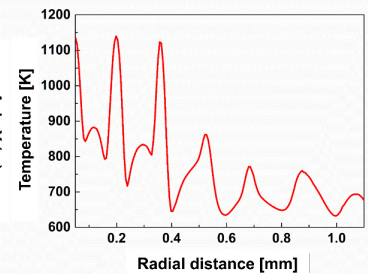

Figure 5. Numerical analysis results of the chamber region for the condition fixed at $400 \mathrm{~mm}$ and $300 \mathrm{~K} \cdot(\mathrm{a}, \mathrm{b})$ temperature contour and profile for a $20^{\circ}$ injection angle and $(c, d)$ temperature contour and profile for a $30^{\circ}$ injection angle.

K combustion air temperature, the maximum and minimum temperatures at the center of the chamber were approximately 2,200 and 1,600 $\mathrm{K}$, respectively. Remarkably, the temperature region over $1,700 \mathrm{~K}$ was widely distributed to the chamber exit. Moreover, the temperature variation was low, and the temperature distribution was maintained over $1,800 \mathrm{~K}$ at the center of the chamber. It was revealed that the increase in combustion air temperature forms a uniform temperature distribution, which provides a conducive combustion environment for alternative waste fuels.

\section{Conclusions}

In this study, we confirmed the thermal flow characteristics inside the combustion chamber with multiple DC torches by using a numerical simulation. This combustion process has been applied to produce the raw material of cement. Thermal plasma was used as the heat source of the combustion system. Through numerical simulation, it was identified that temperatures in the range of 3,000-6,000 $\mathrm{K}$ were formed at the torch exit, and optimized conditions were created by adjusting the chamber width, injection angle, and combustion air temperature. As a result, the optimized design conditions of the chamber are as follows: $400 \mathrm{~mm}$ chamber width, $20^{\circ}$ injection angle, and 1,000

(a) $T(K$

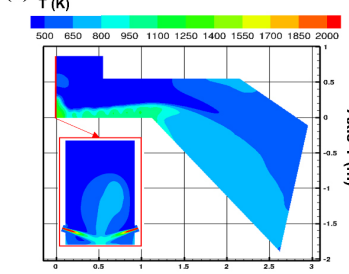

(c) $\mathrm{T}(\mathrm{k})$

xis $X(m)$

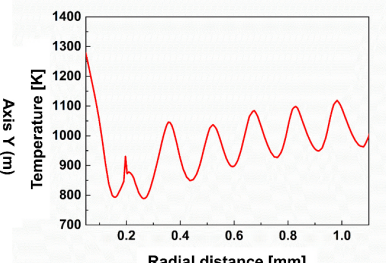

(d)

Radial distance $[\mathrm{mm}]$
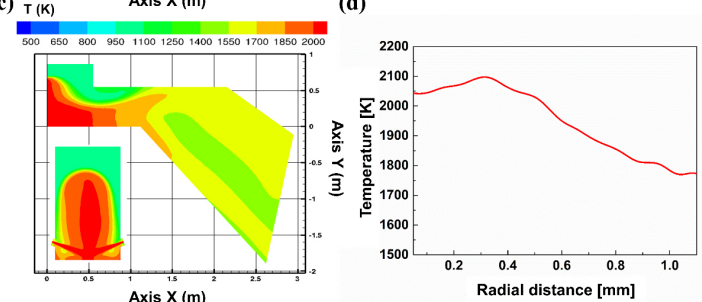

Figure 6. Numerical analysis results of the chamber region for the condition fixed at $400 \mathrm{~mm}$ and $20^{\circ}$ : (a, b) temperature contour and profile for a $300 \mathrm{~K}$ combustion air temperature and (c, d) temperature contour and profile for a $1,000 \mathrm{~K}$ combustion air temperature.

$\mathrm{K}$ combustion air temperature. In spite of the low temperature for combustion air, it is considered that the plasma jets generate a sufficient temperature to treat waste plastics. The optimized design and operating conditions were applied to the actual cement industry, and a treatment capacity of 5 ton/h was achieved for waste plastics.

\section{Acknowledgements}

This work was supported by the National Research Foundation of Korea (NRF) grant funded by the Korean government (MSIT) (NRF2021M3I3A1084958). Part of the work was carried out under the Collaborative Research Project of the Institute of Fluid Science, Tohoku University.

\section{Conflicts of Interest}

The authors declare no conflicts of interest.

\section{ORCID}

Hyeokjun Kang Jeong-Hwan Oh

Daeun Choi

Hidemasa Takana

Sooseok Choi https://orcid.org/0000-0002-5067-5191 https://orcid.org/0000-0002-1426-1354 https://orcid.org/0000-0002-3100-7622 https://orcid.org/0000-0002-4862-9866 https://orcid.org/0000-0002-3957-8956

\section{References}

[1] S. Y. Huh, H. Lee, J. Shin, D. Lee, and J. Jang, Renew. Sust. Energ. Rev. 82, 4091 (2018)

[2] T. Burman, Master thesis, Chalmers University of Technology, 2019.

[3] H. Klee, R. Hunziker, R. van der Meer, and R. Westaway, Greenh. Gas Meas. Manag. 1, 109 (2011)

[4] S. Anand, P. Vrat, and R. P. Dahiya, J. Environ. Manage. 79, 383 (2006).

[5] Y. J. Park, New Renew. Energy 12, 19 (2015).

[6] O. I. Nkwachukwu, C. H. Chima, A. O. Ikenna, and L. Albert Int. J. Ind. Chem. 4, 34 (2013).

[7] D. Glushkov, K. Paushkina, D. Shabardin, P. Strizhak, and N. Gutareva, J. Environ. Manage. 231, 896 (2019). 
[8] N. H. Shah, E. N. Jayswal, and A. H. Suthar, Int. J. Environ. Sci. Technol. 18, 741 (2021).

[9] K. S. Kim and T. H. Kim, J. Appl. Phys. 125, 070901 (2019).

[10] M. Tendler, P. Rutberg, and G. van Oost, Plasma Phys. Control. Fusion 47, A219 (2005).

[11] H. W. Park, W. B. Cha, and S. Uhm, Appl. Chem. Eng. 29, 10 (2018).

[12] S. Choi, D. H. Park, and T. Watanabe, Nucl. Eng. Technol. 44, 21 (2011).

[13] S. Choi, J. M. Park, W. T. Ju, and S. H. Hong, J. Thermal Sci. Technol. 6, 210 (2011).

[14] J. Ko, T. H. Kim, and S. Choi, Plasma Sci. Technol. 21, 064002
(2019).

[15] M. Hur, K. S. Kim, and S. H. Hong, Plasma Sources Sci. Technol. 12, 255 (2003).

[16] B. I. Min, T. H. Kim, and S. Choi, J. Korean Phys. Soc. 74, 785 (2019).

[17] T. H. Kim, Y. H. Lee, M. Kim, J. H. Oh, and S. Choi, IEEE Trans. Plasma Sci. 47, 3366 (2019).

[18] M. Kim, Y. H. Lee, J. H. Oh, S. H. Hong, B. I. Min, T. H. Kim, and S. Choi, Chem. Eng. J. 395, 125148 (2020).

[19] J. H. Oh, Y. H. Lee, T. H. Kim, and S. Choi, Int. J. Plasma Environ. Sci. Technol. 15, e01002 (2021). 